\title{
Comparison of the Predictive Values of Absolute Neutrophil Count, Absolute Band Count, and Toxic Granulation of Neutrophils with Serum Levels of C-reactive Protein for the Diagnosis of Bacterial Infections
}

\author{
Seyed Hamid Hashemi ${ }^{1}$, Hamid Reza Ghasemi Basir ${ }^{2, *}$, Mohammad Ali Seifrabiei ${ }^{3}$, \\ Anahita Saify ${ }^{4}$ \\ ${ }^{1}$ Professor of Infectious Diseases, Brucellosis Research Center, Hamadan University of Medical Sciences, Hamadan, Iran \\ 2 Assistant Professor, Department of Pathology, School of Medicine, Hamadan University of Medical Sciences, Hamadan, Iran \\ ${ }^{3}$ Associate Professor, Department of Community Medicine, School of Medicine, Hamadan University of Medical Sciences, \\ Hamadan, Iran \\ ${ }^{4}$ General Practitioner, Hamadan University of Medical Sciences, Hamadan, Iran
}

* Corresponding Author: Hamid Reza Ghasemi Basir, Department of Pathology, School of Medicine, Hamadan University of Medical Sciences, Hamadan, Iran.Email:hrgb2004@yahoo.com

Received: 08.10 .2017

Accepted: 15.01.2018

\section{How to Cite this Article:}

Hashemi SH, Ghasemi Basir HR,

Seifrabiei MA, Saify A.

Comparison of the Predictive

Values of Absolute Neutrophil

Count, Absolute Band Count, and

Toxic Granulation of Neutrophils with Serum Levels of C-reactive

Protein for the Diagnosis of

Bacterial Infections. Avicenna $J$

Clin Med. 2018; 24(4): 270-276.

DOI: $10.21859 /$ ajcm.24.4.270.

\section{Abstract}

Background and Objective: Correct and early diagnosis of infections contributes to proper treatment and helps prevent unnecessary antibiotic treatment. Thus, we aimed to compare the predictive values of the absolute neutrophil count, band count, and toxic granulation of neutrophils with the serum levels of C-reactive protein (CRP) in bacterial infections.

Materials and Methods: In this descriptive cross-sectional study, we enrolled 200 patients who were admitted to the infectious disease ward of Sina Hospital, Hamadan, Iran, for bacterial infections in the first 6 months of 2016. The participants were chosen using the census sampling method. Before initiating the treatment, to carry out complete blood count (CBC) and quantitative CRP, $5 \mathrm{cc}$ blood was obtained from the patients after obtaining their permission, and the percentages of neutrophils, band cells, and toxic granulation were evaluated in peripheral blood smear. This information and demographic data were collected by a checklist and analyzed by using SPSS, version 16.

Results: The mean age of the patients was 56.26 years (range: 12 to 103 years), and $60.5 \%$ of the participants were male. The most frequent causes of hospitalization were pneumonia, soft tissue infections, sepsis, urinary tract infection, septic arthritis, and dysentery. The means of serum CRP, absolute neutrophil count, and band-cell count were $61.18 \mathrm{mg} / \mathrm{L}, 815.86$ per $\mathrm{mm}^{3}$, and 318.86 per $\mathrm{mm}^{3}$, respectively. The correlation coefficients between quantitative CRP and absolute neutrophil count, band count, and toxic granulation severity were $0.43,0.47$, and 0.47 , respectively.

Conclusion: The results of the present study shows a linear correlation between CRP and the absolute neutrophil count, band count, and toxic granulation, indicating that these variables can replace CRP in the diagnosis of infections. Also, the predictive values of toxic granulation and band count for replacing CRP are equal and higher than that of absolute neutrophil count.

Keywords: C-reactive Protein, Infection, Neutrophil, Toxic Granulation 


\title{
مقايسه ارزش بيشكويى كننده تعداد مطلق نوتروفيل، باندسل و ميزان تو كسيك تر انو لاسيون با سطح سر مى CRP براى تشخيص عفونتهاى باكتريال
}

\author{
سيد حميد هاشمى'، حميد رضا قاسمى بصير r."، محمد على سيف ربيعى '، آناهيتا سيفى \\ ' استاد بيمارى هاى عفونى، مركز تحقيقات بروسلوز، دانشخاه علوم يزشكى همدان، همدان، ايران

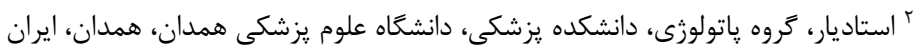

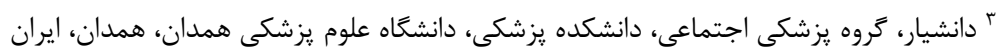

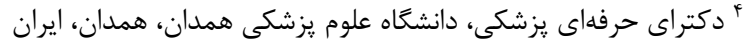

* نويسنده مسئول: حميد رضا قاسمى بصير، كروه ياتولوزى، دانشكده يزشكى، دانشكاه علوم يزشكى همدان، همدان، ايران. ايميل: hrgb2004@yahoo.com

\section{جـيده}

سابقه و هدف: تشخيص صحيح و بلموقع عفونتها منجر به درمان صحيح و زودرس شده و واز درمان دان

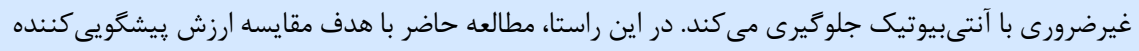

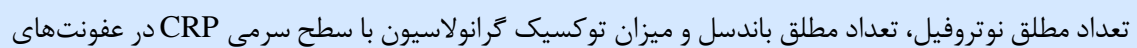
باكتريال صورت كرفت.

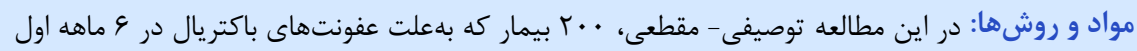

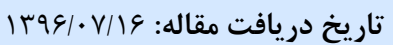

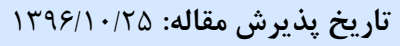
تمامى حقوق نشر براى دانشكاه علوم

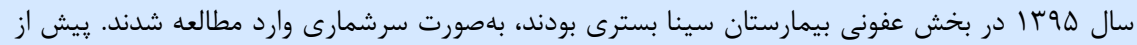

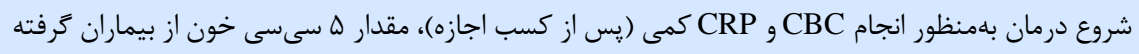

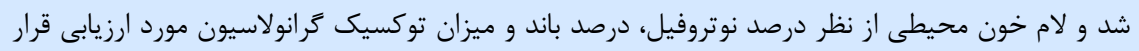

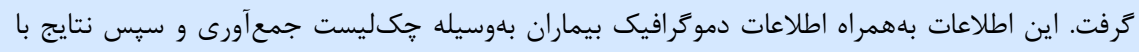

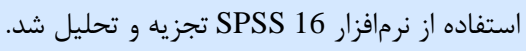

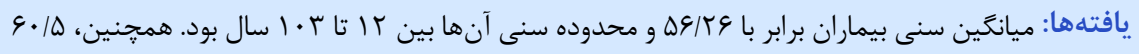

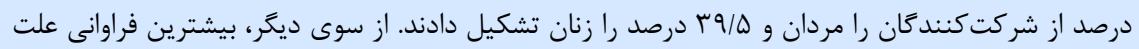

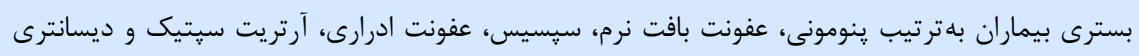

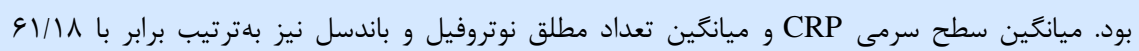

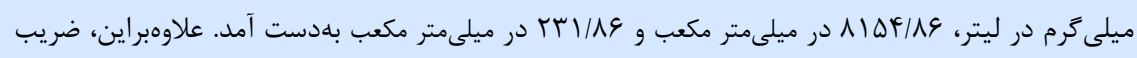

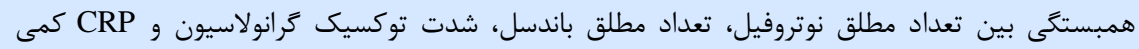

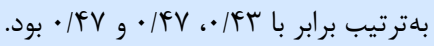

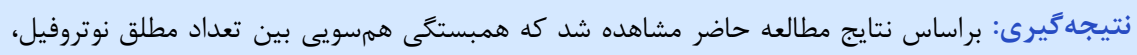

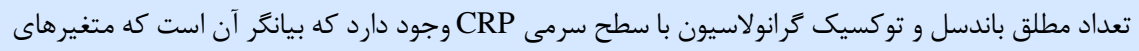

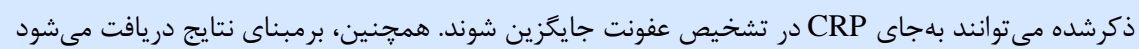

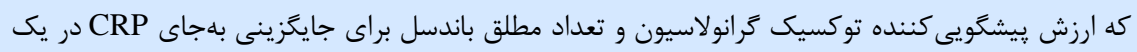
سطح بوده و بيشتر از تعداد مطلق نوتروفيل است. وازگًان كليدى: يروتئين واكنشكر C، توكسيك گرانولاسيون، عفونت، نوتروفيل

كاهى تشخيص صحيح عفونت بسيار مشكل است؛ بهعنوان

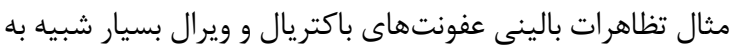

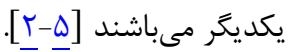

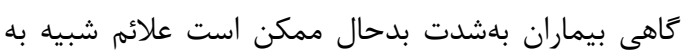

بيمارىهاى عفونى بهدليل امكان درگيرى اركانهاى

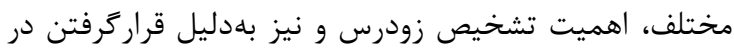

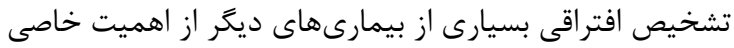

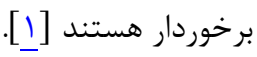


گرانولهاى توكسيك، گرانولهاى سيتويلاسمى آبى تيره تا ارغوانى رنتىى هستند كه ممكن است در در متاميلوسيتها،

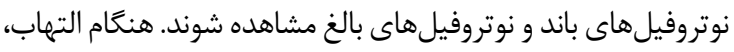
سطح G-CSF) granulocyte colony stimulating factor سرم و Interleukin-6 (IL-6) يلاسما افزايش مىيابد و اين عوامل باعث تحريك تشكيل نوتروفيلهاى حاوى ترانولهاى ناي

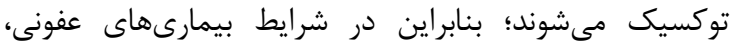

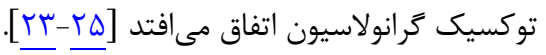
گرانولاسيون توكسيك ممكن است با سطح بالاى تروتئئين

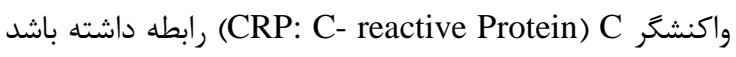
يك واكنش گ CRP .[YT]

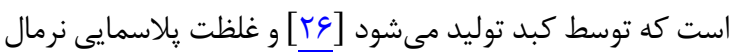

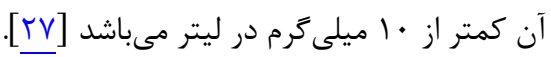

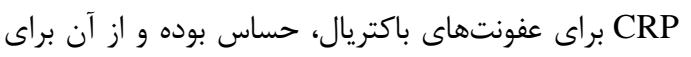

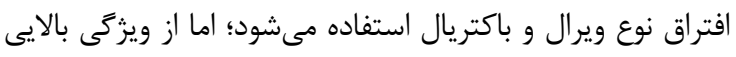

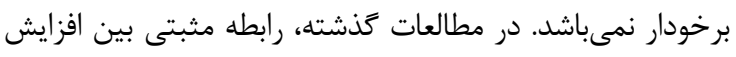

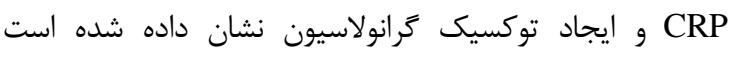

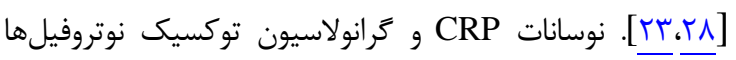

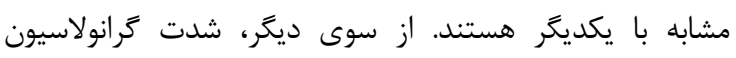

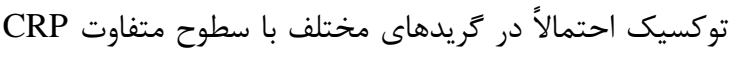

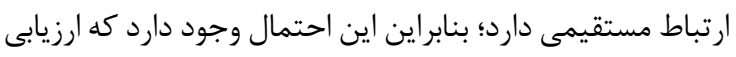

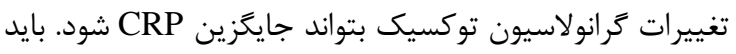
توجه داشت كه اين مسأله بلويزه در مورد بيمارانى كه مشكلات عملكردى كبد دارند، ارزشمند مىباشد [سب].

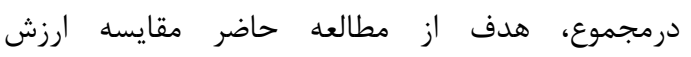

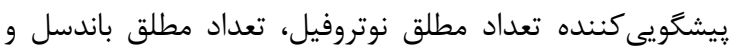

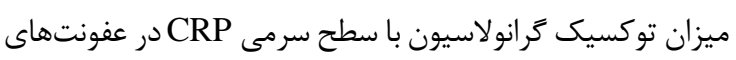

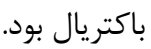

\section{مواد و روشها}

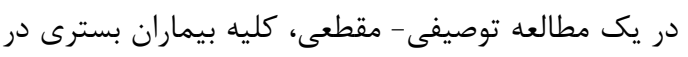
9 ماه اول سال هو با در بخش عفونى بيمارستان سينا همدان

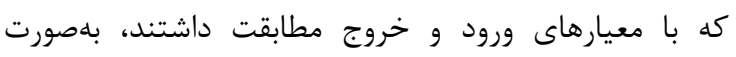
سرشمارى وارد مطالعه شدند. معيارهاى ورود به مطالعه عبارت

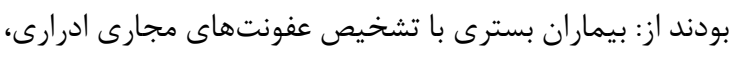

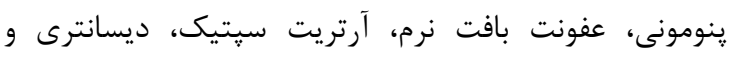

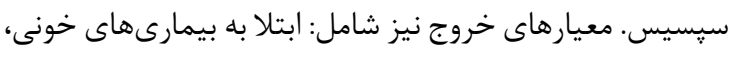

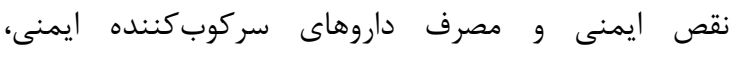
بيمارىهاى عفونى ويروسى و بيمارىهاى كبدى بونى بودند. تشخيص انواع بيمارىهاى عفونى براساس معيارهاى زير صورت كرفت [rq] 1. عفونت مجارى ادرارى: وجود علائم ادرارى بههمراه بيش از 1 إن WBC

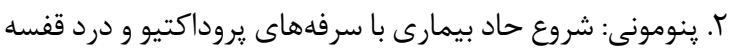

سيسيس را از خود بروز دهند؛ بدون آنكه واقعاً به عفونت خاصى

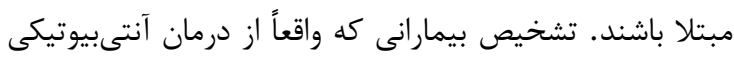

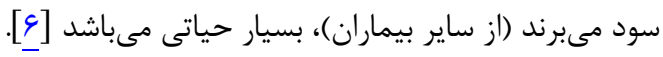

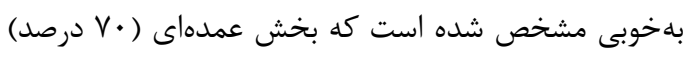

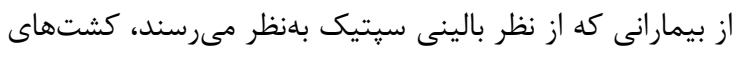

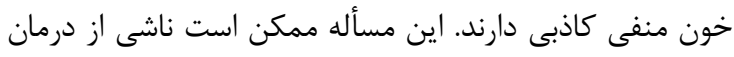

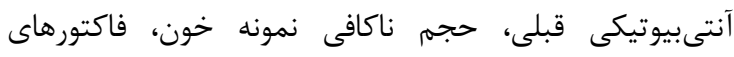

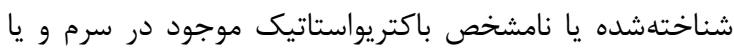

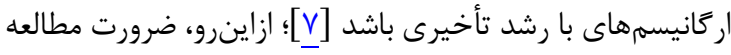
و شناسايى ماركرهاى تشخيصى عفونت و مقايسه آنها با يخديخر

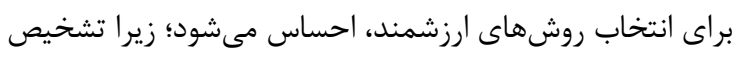

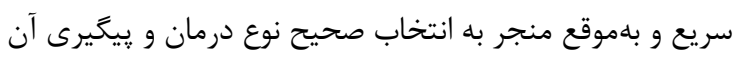

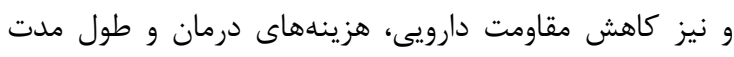
بسترى مىشود [-1_-1].

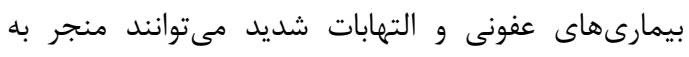

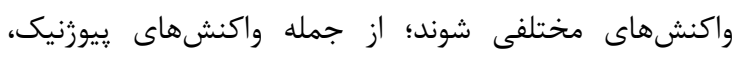

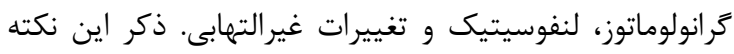

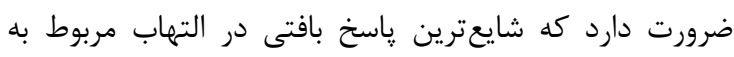

نوتروفيلها است [111]

WBC: در حال حاضر، شمارش كَلبولهاى سفيد خون (White Blood Cell Count

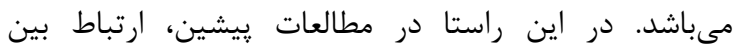

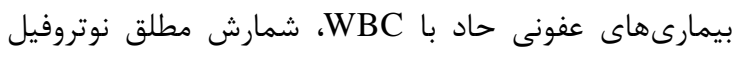
و افزايش نوتروفيلهاى (ANC: Absoluteneutrophil Count)

باند ثابت شده است [11][

نوتروفيل باند يكى از اشكال ردههاى توليدى نوتروفيل النها

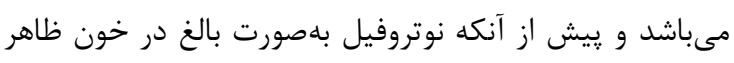

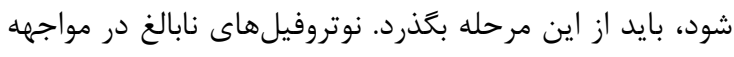

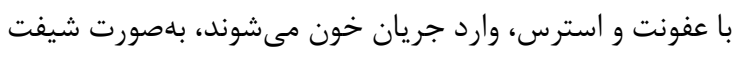

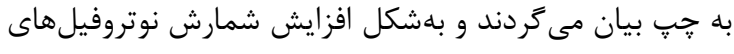

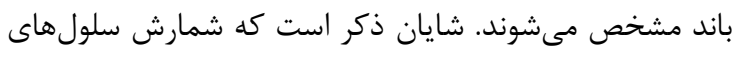

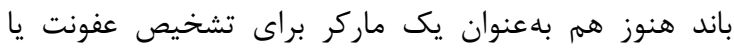

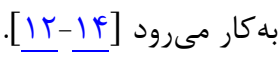

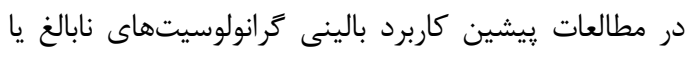
تغييرات در لكوسيتها براى ييشبينى عفونت اثبات شده است؛

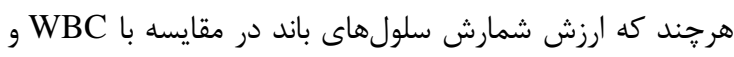

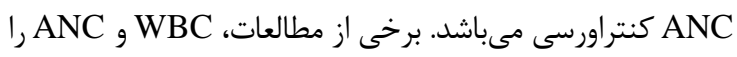
ارزشمندتر از شمارش باندسل دانستهاند [ـ

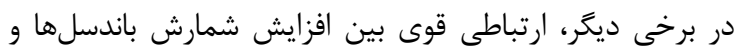

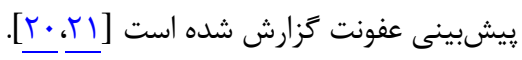

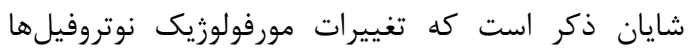

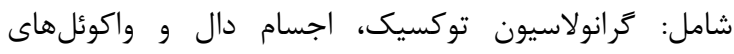
سيتويلاسمى در تشخيص و وِيشبينى عفونت، حساسيت بالايى

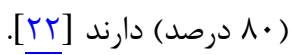


سطح معنادارى نيز كمتر از هـ/• • •عيين گرديد.

يافته ها

در مطالعه حاضر • ب بيمار بخش عفونى با تشخيص عفونتهاى مجارى ادرارى، ينومونى، عفونت بافت نرم، آرتريت

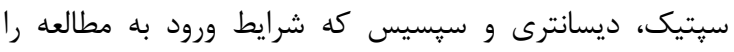
داشتند، بلصورت سرشمارى ارزيابى شدند. لازم به ذكر است كه

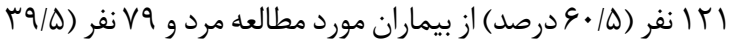

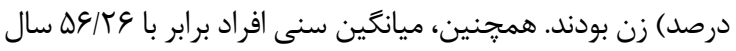

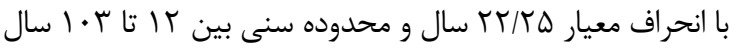

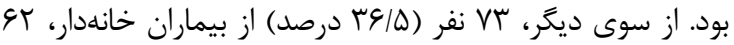

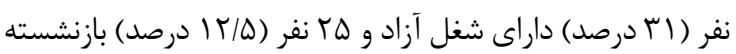

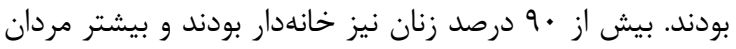

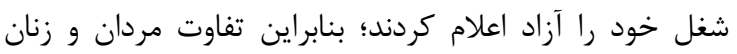

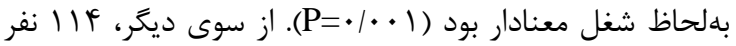

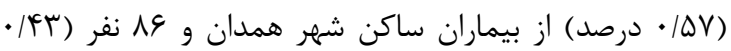

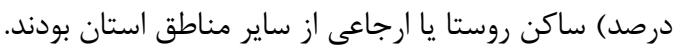

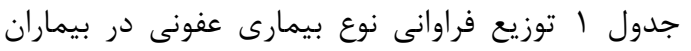

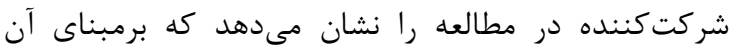

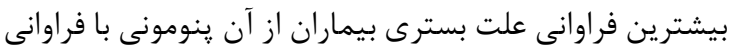

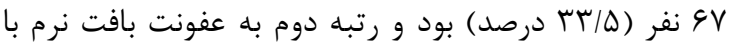

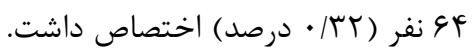

جدول ا: توزيع فراوانى و نوع بيمارى عفونى در بيماران بسترى در بخش عفونى بيمارستان سينا

\begin{tabular}{|c|c|}
\hline تعداد (درصد) & نوع بيمارى \\
\hline$(\Gamma \Gamma / Q) \& V$ & ينومونى \\
\hline$(r T / \cdot) G F$ & عفونت بافت نرم \\
\hline G & ينومونوسيسيس \\
\hline$(1 \cdot \mid \Delta) r \mid$ & عفونت ادرارى \\
\hline$(9 / \cdot)$ IT & يوروسيسيس \\
\hline$(r / \cdot)^{\varphi}$ & ارتريت سيتيك \\
\hline$(Y / \cdot))^{F}$ & ديسانترى \\
\hline$(1 \cdots) \Gamma \cdot$. & جمع \\
\hline
\end{tabular}

ميانگين سطح سرمى CRP، ميانگين تعداد مطلق نوتروفيل

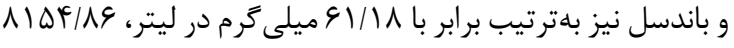

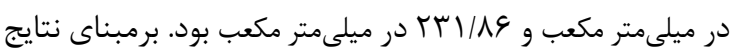

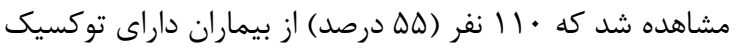

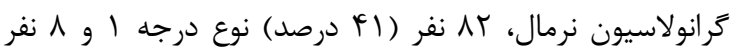

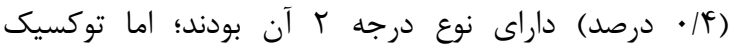

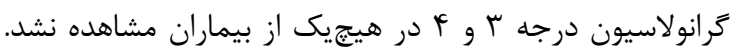

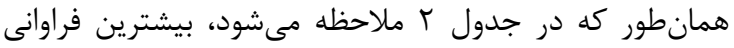

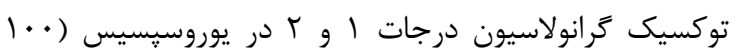

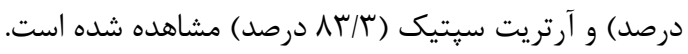

سينه و يا يافتههاى غيرطبيعى در سمع ريه همراه با علائم ارتشاح و انفيلتراسيون جديد در زرافى قفسه سينه كه مطابق با ينومونى است. r. عفونت بافت نرم: بروز علائم و نشانهاى يوسى يوستى و عفونت

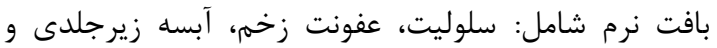
فاشئيت نكروزان

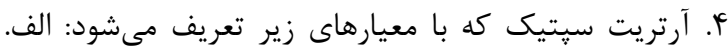

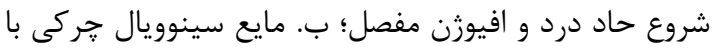

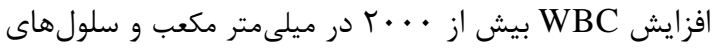

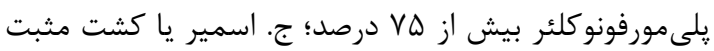

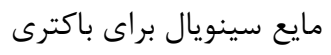

ه. ديسانترى: التهاب روده با اسهال خونى و دفع موكوس درى در كنار تب، درد شكمى و تنسموس همراه با افزايش لكوسيت در مدفوع و جداشدن باكترى ياتوزن از كشت مدفوع

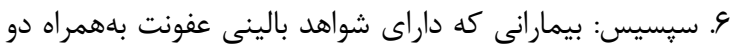

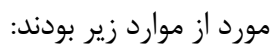

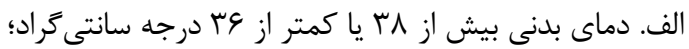

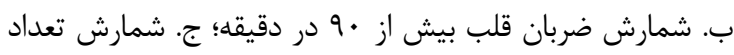

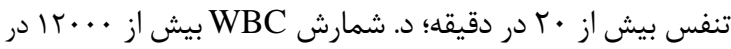

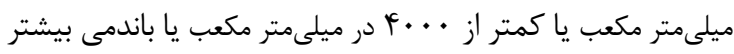

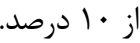

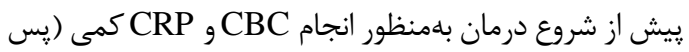

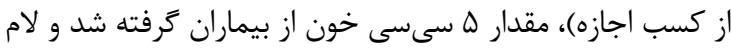

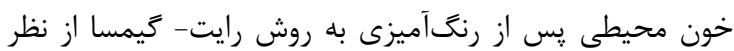

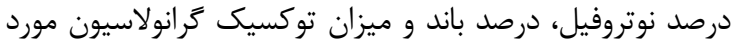

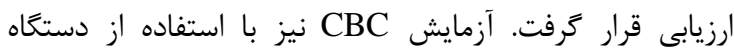

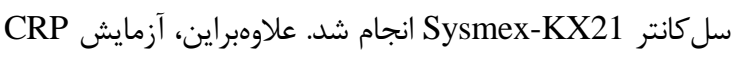
كمى به روش توربيدومترى و با استفاده از دستخاه اتوآنالايزر

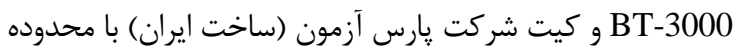

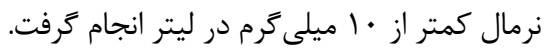

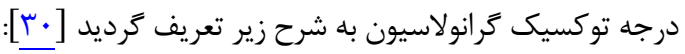
درجه صفر: كرانولهاى طبيعى در نوتروفيلها مشاهده مىشود.

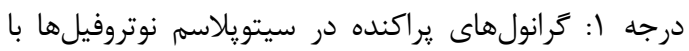
افزايش شدت رنت آنها مشاهده مىشود.

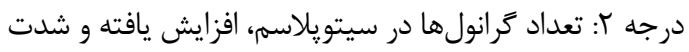
رنت آنها نيز بيشتر شده است.

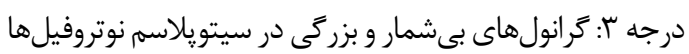
مشاهده مىشود؛ بلهورى كه رنى آنها آبى تيره مىباشد.

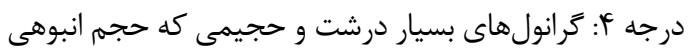

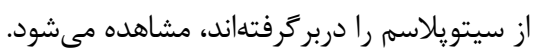

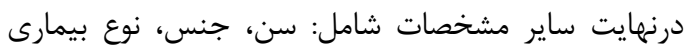

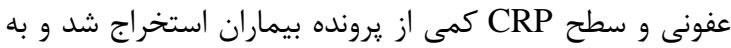

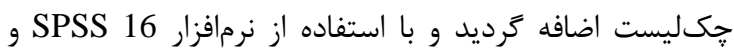
آزمون آمارى ضريب همبستخى Spearman آناليز آمارى شد. 
جدول r: توزيع فراوانى توكسيك ترانولاسيون در افراد شركت كننده در مطالعه برحسب نوع عفونت

\begin{tabular}{|c|c|c|c|c|c|c|c|}
\hline ينوموسبسيس & يوروسبِسيس & ديسانترى & آرتريت سيتيك & عفونت بافت نرم & ينومونى & عفونت ادرارى & درجه \\
\hline$(\Gamma \wedge / \Delta))$. & $(\cdot \cdot / \cdot) \cdot$ & $(V \Delta / \cdot) r$ & $(\mid \& / V) \mid$ & $(G \wedge / V) F F$ & $(\Delta G / V)$ r & $(99 / V) \mid f$ & صفر \\
\hline$(\Delta H / \Lambda) \backslash F$ & $(\Lambda \Gamma / \Gamma) 1$. & $(T \Delta / \cdot))$ & $(\Lambda \mu / \widetilde{\mu}) \Delta$ & $(T \wedge / I) \backslash \wedge$ & q & $(r \mu / \Lambda) \Delta$ & يك \\
\hline$(V / V) r$ & $(19 / V) Y$ & $(\cdot \cdot / \cdot) \cdot$ & $(\cdot \cdot / \cdot) \cdot$ & $(r / l) r$ & $(\cdot \cdot / \cdot) \cdot$ & $(9 / \Delta) r$ & دو \\
\hline$(1 \cdot \cdot / \cdot)$ TG & $(1 \cdot \cdot / \cdot) \mid r$ & $(1 \cdot \cdot / \cdot)^{f}$ & $(1 \cdot \cdot / \cdot)^{9}$ & $(1 \cdot \cdot / \cdot) g t$ & $(1 \cdot \cdot / \cdot) \& V$ & $(1 \cdot \cdot / \cdot) Y I$ & جمع كل \\
\hline
\end{tabular}

كه براساس آن، همبستخى همسو؛ اما نه هندان قوى بين

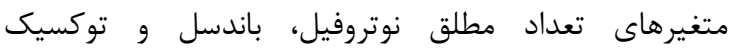

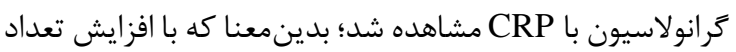

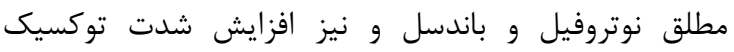

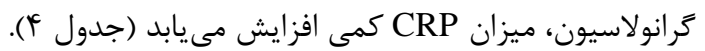

در جدول ب، توزيع شاخصهاى مركزى و زيراكندگى

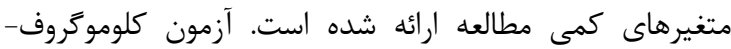

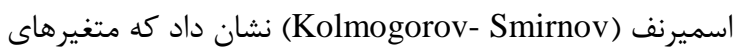
كمى از توزيع نرمال يُيروى نمى كنند. علاوهبراين، بهمنظور

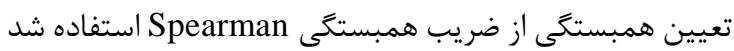

جدول ب: توزيع شاخص هاى مر كزى و براكندكى متغيرهاى كمى در بيماران مورد مطالعه بسترى در بخش عفونى بيمارستان سينا

\begin{tabular}{|c|c|c|c|c|}
\hline بيشينه & كمينه & انحراف معيار & ميانغين & 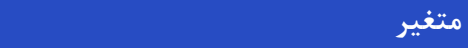 \\
\hline$f \cdot 1 \ldots$ & rl.. & $F \notin F I / \wedge D$ & $1 \cdot v \cdot 9$ & WBC (در ميلىمتر مكعب) \\
\hline IT. & $\Delta$ & $\mid f</ 91$ & $41 / 11$ & CRP (ميلى گرم در ليتر) ) \\
\hline 90 & re & $15 / 19$ & $V T / \Delta T$ & درصد نوتروفيل \\
\hline$\Delta F$ & r & $11 / r \wedge$ & $1 N / 0$ & درصد لنفوسيت \\
\hline ir & $\cdot$ & $r / \cdot V$ & $1 / 4 V$ & باندسل (در ميلىمتر مكعب) \\
\hline fir.. & $1 \cdot 19$ & $\Delta I V \& \mid \wedge \Delta$ & $\Lambda \mid \Delta F / \Lambda G$ & تعداد مطلق نوتروفيل (در ميلىمتر مكعب) \\
\hline rт人 & · & F्I/बr & THI/AG & تعداد مطلق باندسل (در ميلىمتر مكعب) \\
\hline $1 \cdot r$ & it & $T T / T \Delta$ & $\Delta \varphi / T \varphi$ & سن (بر حسب سال) س \\
\hline
\end{tabular}

لازم به ذكر است كه مطالعه حاضر در ارتباط با گروه سنى

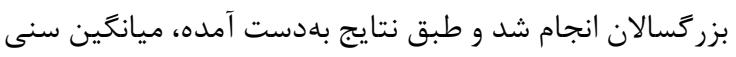

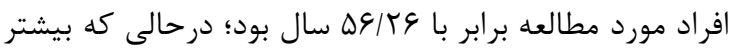
مطالعات كذشته در مورد گروه سنى اطفال و نوزادان انجام

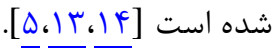

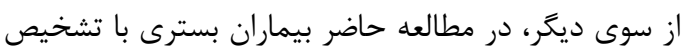

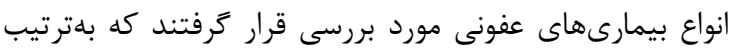

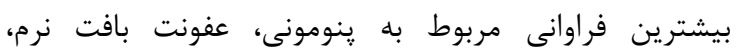

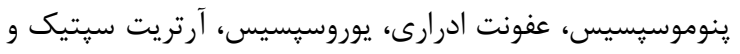

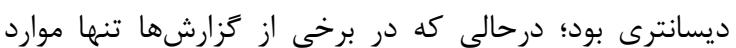

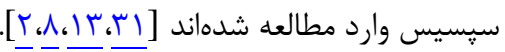

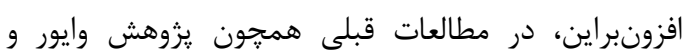

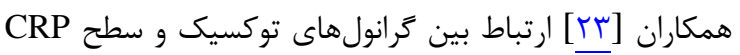
در بيمارىهاى عفونى و التهابى شرح داده شده است؛ اما ارتباط بين شدت توكسيك كرانولاسيون و افزايش CRP در مر مطالعات كمى مورد بررسى قرار گرفته است. در اين ارتباط، نتايج مطالعه

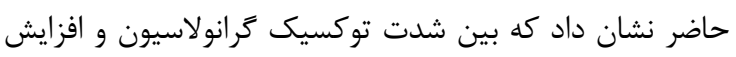

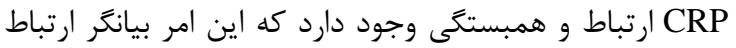

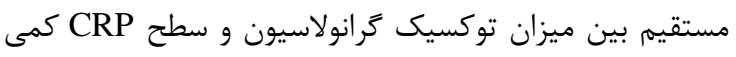

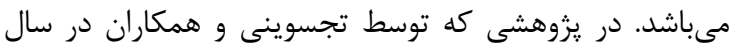

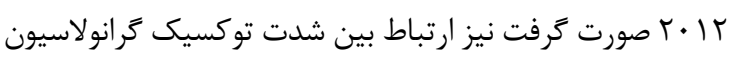

جدول F) ضريب همبستكى بين تعداد مطلق نوتروفيل، تعداد

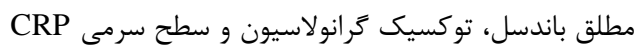

\begin{tabular}{|c|c|}
\hline سطح سرمى CRP & متغير \\
\hline $\mathrm{P}=\cdot / \cdot \mid \mathrm{r}_{\mathrm{s}}=\cdot / \mathrm{fr}$ & تعداد مطلق نوتروفيل \\
\hline $\mathrm{P}=\cdot / \cdot \mid \boldsymbol{r}_{\mathrm{s}}=\cdot / \mathrm{fV}$ & تعداد مطلق باندسل \\
\hline $\mathrm{P}=\cdot / \cdots \mid \mathrm{r}_{\mathrm{s}}=\cdot / 4 \mathrm{~V}$ & شدت توكسيك گرانولاسيون \\
\hline
\end{tabular}

عفونتها در موارد بسيارى باعث مصرف گسترده و نابهجاى

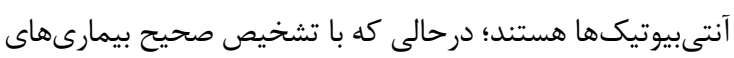

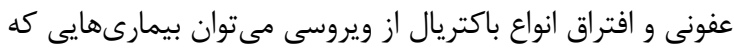

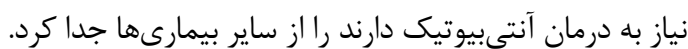

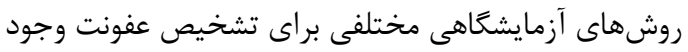

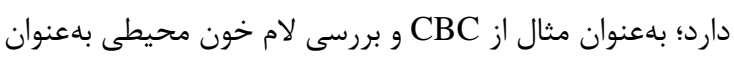
يك آزمايش ضرورى در تشخيص عفونتها استفاده مى بـون.

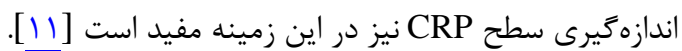

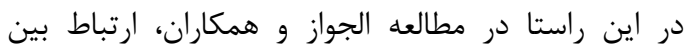
عفونتهاى باكتريال و افزايش تعداد لكوسيت، تعداد مطلق دران

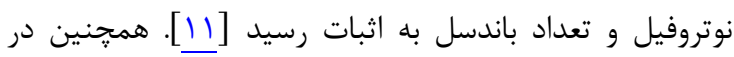

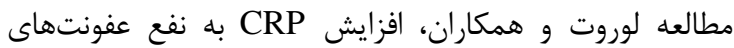

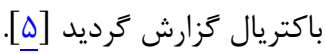


دسترس نبوده و يا بهدليل مشكلات عملكردى كبد، مقادير آن

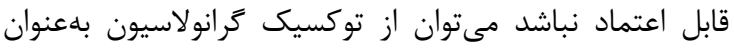
جايخزين مناسب استفاده كرد.

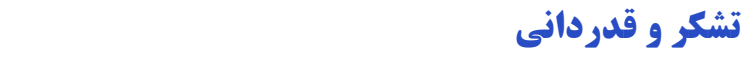

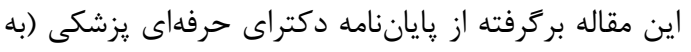

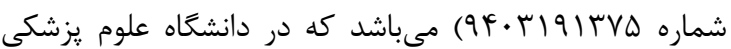
همدان انجام كرفته است. بدينوسيله نويسندگان از همكارى كاركنان بخش عفونى و آزمايشكاه بيمارستان سينا همدان كه در آندام

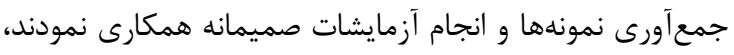

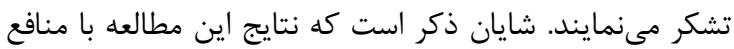
نويسندگان در تعارض نمىباشد.

\section{REFERENCES}

1. Khabbaz R, Bell BP, Schuchat A, Ostroff SM, Moseley R, Levitt A, et al. Emerging and reemerging infectious disease threats. In: Bennett J, Dolin R, Blaser MJ, editors. Principles and practice of infectious diseases. Philadelphia: Elsevier Saunders; 2015. P. 158-78.

2. Martin G, Mannino D, Eaton S, Moss M. The epidemiology of sepsis in the United States from 1979 through 2000. N Engl J Med. 2003;348(16):1546-54. PMID: 12700374 DOI: 10.1056/NEJMoa022139

3. Balk RA. Systemic inflammatory response syndrome (SIRS): where did it come from and is it still relevant today? Virulence. 2014;5(1):20-6. PMID: 24280933 DOI: 10.4161/ viru. 27135

4. World Health Organization. Overcoming antimicrobial resistance. Geneva: World Health Organization; 2000.

5. Lorrot M, Moulin F, Coste J, Ravilly S, Guerin S, Lebon P, et al. Procalcitonin in pediatric emergencies: comparison with C-reactive protein, interleukin 6 and interferon alpha in the differentation between bacterial and viral infections. Presse Med. 2000;29(3):128-34. PMID: 10686961

6. Cals JW, Butler CC, Hopstaken RM, Hood K, Dinant GJ. Effect of point of care testing for $\mathrm{C}$ reactive protein and training in communication skills on antibiotic use in lower respiratory tract infections: cluster randomised trial. $B M J$. 2009;338:b1374. PMID: 19416992

7. Cursons RT, Jeyerajah E, Sleigh JW. The use of polymerase chain reaction to detect septicemia in critically ill patients. Crit Care Med. 1999;27(5):937-40. PMID: 10362416

8. Sands KE, Bates DW, Lanken PN, Graman PS, Hibberd PL, Kahn KL, et al. Epidemiology of sepsis syndrome in 8 academic medical centers. JAMA. 1997;278(3):234-40. PMID: 9218672

9. Harris KA, Hartley JC. Development of broad-range $16 \mathrm{~S}$ rDNA PCR for use in the routine diagnostic clinical microbiology service. J Med Microbiol. 2003;52(Pt 8):68591. PMID: 12867563 DOI: $10.1099 / j m m .0 .05213-0$

10. Rothman RE, Majmudar MD, Kelen GD, Madico G, Gaydos CA, Walker T, et al. Detection of bacteremia in emergency department patients at risk for infective endocarditis using universal 16S rRNA primers in a decontaminated polymerase chain reaction assay. J Infect Dis. 2002;186(11):1677-81. PMID: 12447747 DOI: $10.1086 / 345367$

11. Al-Gwaiz LA, Babay HH. The diagnostic value of absolute neutrophil count, band count and morphologic changes of neutrophils in predicting bacterial infections. Med Princ Pract. 2007;16(5):344-7. PMID: 17709921 DOI: 10.1159/ 000104806

12. Cornbleet PJ. Clinical utility of the band count. Clin Lab Med. 2002;22(1):101-36. PMID: 11933571

13. Newman TB, Draper D, Puopolo KM, Wi S, Escobar GJ. Combining immature and total neutrophil counts to predict early onset sepsis in term and late preterm newborns: use of the I/T2. Pediatr Infect Dis J. 2014;33(8):798-802. PMID:

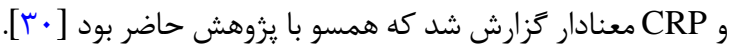
همجنين در يروهش دانانجاى و همكاران (1 (1 • (1)، توكسيك كرانولاسيون بهعنوان يك ماركر سيتيسمى نوزادى در كنار

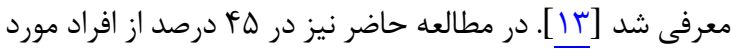

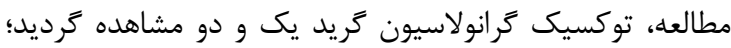
اما در هD درصد ديخر مشاهده نشد؛ بنابراين با توجه به مطالعات

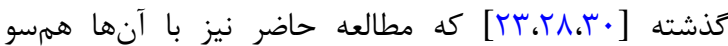
مىباشد، دريافت مىشود كه توكسيك زرانولاسيون مىتواند بهعنوان يكى انديكاتور بهجاى CRP در تشخيص بيمارىهاى عفونى بـ كار رود.

$$
\text { نتيجه كيرى }
$$

\section{DOI: $10.1097 / I N F .0000000000000297$}

14. Zarkesh M, Sedaghat F, Heidarzadeh A, Tabrizi M, BolookiMoghadam K, Ghesmati S. Diagnostic value of IL-6, CRP, WBC, and absolute neutrophil count to predict serious bacterial infection in febrile infants. Acta Med Iran. 2015;53(7):408-11. PMID: 26520627

15. Novac R. The beleaguered band coun. Clin Lab Med. 1993;13(4):895-903. PMID: 8313688

16. Rimarenko S, Castella A, Salzberg MR, Strand CL. Evaluation of the automated leukocyte differential count in emergency department patients. Am J Emerg Med. 1987;5(3):187-9. PMID: 3580048

17. Shapiro MF, Greenfield S. The complete blood count and leukocyte differential count: an approach to their rational application. Ann Intern Med. 1987;106(1):65-74. PMID: 3538968

18. Krause JR. Automated differentials in the hematology laboratory. Am J Clin Pathol. 1990;93(Suppl 1):11-6. PMID: 2180276

19. Wenz B, Gennis P, Canova C, Burns ER. The clinical utility of the leukocyte differential in emergency medicine. $A m J$ Clin Pathol. 1986;86(3):298-303. PMID: 3751994

20. Mare TA, Treacher DF, Shankar-Hari M, Beale R, Lewis SM, Chambers DJ, et al. The diagnostic and prognostic significance of monitoring blood levels of immature neutrophils in patients with systemic inflammation. Crit Care. 2015;19:57. PMID: 25887201 DOI: 10.1186/s13054015-0778-Z

21. Benez EI. Hematologic response to acute inflammation: the band neutrophil revisited. Tex Med. 1990;86(4):26-8. PMID: $\underline{2186500}$

22. Seebach JD, Morant R, Ruegg R, Seifer L, Fehr J. The diagnostic value of the neutrophil left shift in predicting inflammatory and infectious diseases. Am J Clin Pathol. 1997;107(5):582-91. PMID: 9128272

23. van de Vyver A, Delport EF, Esterhuizen M, Pool R. The correlation between C-reactive protein and toxic granulation of neutrophils in the peripheral blood. S Afr Med J. 2010; 100(7):442-4. PMID: 20822591

24. Kawakami M, Tsutsumi H, Kumakawa T, Abe H, Hirai M, Kurosawa $\mathrm{S}$, et al. Levels of serum granulocyte colonystimulating factor in patients with infections. Blood. 1990;76(10):1962-4. PMID: 1700729

25. Struzyna J, Pojda Z, Braun B, Chomicka T, Sobiczewska E, Wremel J. Serum cytokine levels (IL-4, IL-6, IL-8, G-CSF) in burned patients. Burns. 2000;21(6):437-40. PMID: $\underline{8554685}$

26. Harrington JM, Chou HT, Gutsmann T, Gelhaus C, Stahlberg $\mathrm{H}$, Leippe $\mathrm{M}$, et al. Membrane activity of a C-reactive protein. FEBS Lett. 2009;583(6):1001-5. PMID: 19230837 DOI: 10.1016/j.febslet.2009.02.019

27. Marnell L, Mold C, Du Clos TW. C-reactive protein: ligands, receptors and role in inflammation. Clin Immunol. 
2005;117(2):104-11. PMID: 16214080 DOI: $10.1016 /$ j.clim. 2005.08 .004

28. Kabutomori O, Kanakura Y, Watani Y. Toxic granulation neutrophils and C-reactive protein. Arch Intern Med. 2001;160(21):3326-7. PMID: 11088097

29. Fauci AS. Harrison 's principles of internal medicine. $18^{\text {th }}$ ed. New York: MCGraw-Hill; 2012. P. 749-1825.
30. Tejeswini V, Kande S, Premalatha P. Correlation of granularity index with toxic granulation of neutrophils by manual microscopy and C-reactive protein. J Dental Med Sci. 2012;3(2):35-9.

31. Dhananjay BS, Nandaa SK. Comparison of biochemical and pathological markers in neonates with sepsis and neonates without sepsis. Int J Biol Med Res. 2011;2(4):1131-4. 